\title{
Weight Perception and Diet Behavior of Japanese and Russian Adolescent Girls
}

\author{
Hiromi Inaba ${ }^{1,2^{*}}{ }^{\circ}$, Marina F. Rziankina ${ }^{3}$, Svetlana A. Kostromina ${ }^{3}$, Genki Sakauchi', Reina Ito ${ }^{2}$, \\ Misaki Kaiwa1,5, Saya Natsui ${ }^{5}$, Narumi Ishii5, Toshiko Saito², Kousuke Takano6, \\ Konstantin V. Zhmerenetsky ${ }^{3}$, Kazuo Ishigami6 \\ ${ }^{1}$ Center for Nutrition Sciences, Niigata University of Health and Welfare, Niigata, Japan \\ ${ }^{2}$ Department of Health and Nutrition, Niigata University of Health and Welfare, Niigata, Japan \\ ${ }^{3}$ Department of Outpatient Pediatrics with Pediatric Infectious Disease Course, Far Eastern State Medical University, Khabarovsk, \\ Russia \\ ${ }^{4}$ Kaetsu Hospital, Niigata, Japan \\ ${ }^{5}$ Graduate School of Health and Welfare, Niigata University of Health and Welfare, Niigata, Japan \\ ${ }^{6}$ Department of Health Informatics, Niigata University of Health and Welfare, Niigata, Japan \\ Email: ^inaba@nuhw.ac.jp
}

How to cite this paper: Inaba, H., Rziankina, M.F., Kostromina, S.A., Sakauchi, G., Ito, R., Kaiwa, M., Natsui, S., Ishii, N., Saito, T., Takano, K., Zhmerenetsky, K.V. and Ishigami, K. (2021) Weight Perception and Diet Behavior of Japanese and Russian Adolescent Girls. Health, 13, 405-415. https://doi.org/10.4236/health.2021.134033

Received: February 14, 2021

Accepted: April 18, 2021

Published: April 21, 2021

Copyright $\odot 2021$ by author(s) and Scientific Research Publishing Inc. This work is licensed under the Creative Commons Attribution International License (CC BY 4.0).

http://creativecommons.org/licenses/by/4.0/

\begin{abstract}
Niigata City in Japan and Khabarovsk City in Russia signed a sister city agreement in 1965 and have been interacting with each other for a long time. We have been conducting comparative research on the elderly between the two cities, but there is no research on the young. Distorted perception of body weight and unnecessary dieting behavior in adolescent girls is considered a problem in both Japan and Russia. Therefore, the purpose of this study was to clarify the distortion of weight perception and diet behavior of adolescent girls in both the countries. In addition, it was decided to investigate the eating habits of people in both the countries. In total, 195 15-year-old girls from Niigata, Japan (October 2020) and 286 girls from Khabarovsk, Russia (February 2017) were surveyed. The questionnaire used was an excerpt from the World Health Organization survey on the health behavior of school-age children. The proportion of Japanese adolescent girls who perceived themselves as overweight (distorted body weight perception) was $60.5 \%$, which was significantly higher than that of Russian adolescent girls at $30.1 \%$ ( $\mathrm{p}<$ 0.001 ). In addition, the prevalence of weight loss behavior in Japan was $34.9 \%$ ( $\mathrm{n}=68)$, which was significantly higher than that in Russia with $27.3 \%$ ( $\mathrm{n}=$ 78) $(\mathrm{p}<0.001)$. Adolescent girls in Japan had more serious problems with weight perception, but had fewer problems with breakfast and vegetable intake habits than those in Russia. From a young age, perception of correct body shape and establishment of eating habits are important not only for current health but also for future health. We need to carefully educate ado-
\end{abstract}


lescent girls that their body undergoes major changes through secondary sexual characteristics during adulthood.

\section{Keywords}

Weight Perception, Eating Habits, Adolescent, Breakfast

\section{Introduction}

In Japan, a high proportion of women are thin from adolescence into their 20s, which is a social problem [1]. In 2013, the Ministry of Health, Labour and Welfare announced, "The second term of National Health Promotion Movement in the twenty-first century (Health Japan 21, the second term)," hereinafter "National Movement from 2013 fiscal year to 2022 fiscal year" as a basic policy to comprehensively advance the promotion of health among its people, with the goal of reducing the percentage of women in their 20s who are thin to less than $20 \%$ [2]. As a result, according to the 2018 National Health and Nutrition Examination Survey, the percentage of women in their 20s who were thin was $19.8 \%[3]$.

It is known that thinness and obesity are harmful and have a negative effect on health. Being thin during adolescence not only impairs one's own health but also affects the next generation. For example, thin women have low bone density [4] and frequent menstrual irregularities [5]. In addition, thin women are reported to have a higher risk of giving birth to low-birth-weight infants [6] [7]. To reduce the proportion of thin women in their 20s, healthy eating behaviors of adolescents and teenagers are important.

Comparing 22 countries in Europe, North America, South America, and Asia, female college students in Asia, including Japan, are more likely to overestimate their weight and are most likely to lose weight [8]. Among the Japanese, adolescent girls living in metropolitan areas have a lower average body mass index (BMI) and an ideal BMI than those living in towns [8]. We also know that women who over-recognize their weight (perceive themselves as obese, even though they are not obese) want to lose weight, and Japanese adolescent girls are required to correctly recognize their weight [9].

Many young people are worried about their body shape and size due to social pressure to fit their skinny body ideals [10] [11] [12]. The media are full of messages about the latest diets and quick fixes for weight loss. As a result, many young people repeatedly turn their diets on and off and engage in unhealthy weight management behavior. Neumark-Sztainer D. et al. reported that diet and unhealthy weight management behavior in adolescence are a predictor of significant weight gain over time [13].

The 2013/2014 Health Behavior in School-aged Children (HBSC) study showed that overall, $14 \%-18 \%$ of adolescents aged 11 to 15 years are on a diet 
or doing something else to lose weight [14]. According to the national nutrition statistics, $21.6 \%$ of normal weight girls aged 15 - 19 years and $6.5 \%$ of underweight girls were trying to lose weight [15], and Hayashi et al. reported that $68.6 \%$ of normal weight girls in this age group are on a diet [9].

Attempts to lose weight by adolescents are strongly defined not only by their weight status, but also by their perception of gender, age, and of what constitutes being overweight [16]. Overweight perception is more common among girls than among boys, and it has been shown that girls eat breakfast less often than boys, so skipping breakfast is one of their weight management behaviors [17]. Adolescents' perception of body weight is an important factor associated with an unhealthy diet. Focusing on physical perception and daily breakfast intake is important for the development of healthy adolescent food-consuming behavior and tracking into adulthood. Therefore, the dietary habits of children and adolescents are of concern because the behaviors adopted during childhood are likely to continue into adulthood [18] [19].

Niigata City entered into a sister city tie-up with Khabarovsk City in 1965 and has been interacting with them for over 50 years. A joint study with the city of Khabarovsk on living functions and the risk of long-term care for the elderly has already been reported [20]. In addition, there were no international reports on weight recognition or eating habits of adolescent girls living in Khabarovsk, Russia.

The purpose of this study was to clarify the BMI, weight perception, and eating habits of adolescent girls in Niigata City, Japan and Khabarovsk City, Russia.

\section{Methods}

\subsection{Participants}

A cross-sectional study was carried out among adolescent schoolgirls from both the countries. The participants aged 15 years old were chosen for this study in order to match the age targeted by HBCS. A high school with the largest number of students in Niigata Prefecture was selected and girls were invited to participate $(n=195)$ during February 2020. Adolescents of the same age in Khabarovsk City were invited to participate $(n=286)$ during October 2017. Permission was obtained from the principals of both the schools. Students were clarified about details of the study and asked to take the explanatory document home. They were asked to answer the questionnaire only when both, themselves and their parents, agreed to participate in the survey.

\section{Questionnaire and Anthropometry}

The questionnaire used in this study was adapted from a questionnaire used by the World Health Organization (WHO) Regional Office for Europe in collaboration with HBSC, which is administered every 4 years in 50 countries and regions across Europe and North America [21].

This questionnaire consisted of different packets of questions, concerning height, weight, perception of body weight, and eating habits relevant for this 
study. BMI was calculated from self-reported height and weight. These questions were posed the same way as those in the WHO Survey on HBSC [21]. To assess the perception of body weight, we asked the HBSC question: "Do you think your body is ..." Responses were categorized on a five-point Likert scale ranging from "Much too thin" to "Much too fat." A perception of being overweight was defined for responses of "Much too fat" or "A bit too fat." We defined dieting behavior based on answers to the HBSC question "At present, are you on a diet or doing something else to lose weight?" and based on the response "Yes, I am on a diet." Eating habits were defined as the ways in which the adolescents consumed meals and foods. Meal and food consumption data were obtained by asking students how frequently they consumed breakfast, fruits, vegetables, snacks, sweets, and soft drinks (contain sugar) in a week, using six-point Likert scales as in the HBSC study. Skipping breakfast was defined as the consumption of main meals less than five times during a school week.

\subsection{Statistical Analysis}

Data were entered into the $\mathrm{R}$ (version 4.0.2.) statistics program. For country differences, we used the chi-square test or Fisher's exact test for non-parametric variables. When $\mathrm{p}<0.05$ in the Fisher's exact test, multiple comparison was performed as a post-hoc test and corrected by the holm method. Height, weight, and BMI were t-tested between the two countries. Level of significance was set at 0.05 for all analyses.

\subsection{Ethical Considerations}

An explanatory document on the research was distributed and also explained orally. The research instructions included the purpose of the study, content and how the information obtained would be handled, and that participation was voluntary and there would be no disadvantages to high school life if the student refused to participate. No personally identifiable information, such as names or school registration numbers, was included. The study complies with the Declaration of Helsinki.

\section{Results}

The height of the Russians was $165.3 \pm 5.9 \mathrm{~cm}$, while that of the Japanese was $158.1 \pm 5.6 \mathrm{~cm}$ (Cohen's $\mathrm{d}=1.245,95 \% \mathrm{CI}$; $1.046-1.444$ ), which was significantly lower. The weight of the Russians was $54.8 \pm 7.3 \mathrm{~kg}$, while that of the Japanese was $50.1 \mathrm{~kg} \pm 5.3 \mathrm{~kg}$ (Cohen's $\mathrm{d}=0.715,95 \% \mathrm{CI}$; 0.527 - 0.903), which was significantly lower. However, regarding BMI, the Russians had $20.0 \pm 2.2$ $\mathrm{kg} / \mathrm{m}^{2}$, while the Japanese had $20.0 \pm 1.8 \mathrm{~kg} / \mathrm{m}^{2}$, showing no significant difference between the two countries (Cohen's $d=0.128,95 \% \mathrm{CI} ;-0.311-0.055$ ). Physical characteristics of Japanese and Russian adolescents by perception of body weight are shown in Table 1 . The groups are classified into four parts: Group 0, adolescents who perceived themselves as not fat and not overweight; 
Group 1, adolescents who perceived themselves as fat and real weight was overweight/obese; Group 2, adolescents who perceived themselves as not fat but real weight was overweight/obese; Group 3, adolescents who perceived themselves as fat, but real weight was not overweight/obese.

Body weight congruence among adolescents in Japan and Russia is shown in Figure 1. Japan's Group 3 was $60.5 \%$, more than double than that of Russia's $30.1 \%$. The Japanese prevalence of weight reduction behavior was $34.9 \%$ ( $\mathrm{n}=$ $68)$, which was significantly higher than Russia's 27.3\% $(\mathrm{n}=78)(\mathrm{p}<0.001)$. Table 2 shows the intake habits during breakfast and the intake of fruits, vegetables, sweets, and soft drinks containing sugar, separated into Japan and Russia. $83.1 \%$ of the adolescent Japanese girls ate breakfast daily on weekdays, which was significantly higher than $65.7 \%$ of Russians ( $p<0.001$ ). The percentage of Japanese adolescents who eat fruit every day was $17.4 \%$, which was significantly lower than the Russian value of $28.3 \%(p=0.006)$. On the other hand, the frequency of vegetable intake was $66.2 \%$ in Japan, whereas it was $32.2 \%$ in Russia (p $<0.001)$. There was no significant difference between the two countries with

Table 1. Physical characteristics of Japanese and Russian adolescents by body weight perception.

\begin{tabular}{|c|c|c|c|c|c|c|c|c|c|c|c|}
\hline \multirow[b]{2}{*}{ Group $^{1)}$} & \multicolumn{5}{|c|}{ Japan } & \multicolumn{5}{|c|}{ Russia } & \multirow[b]{2}{*}{ p-value ${ }^{2}$} \\
\hline & $\begin{array}{c}\text { Group } 0 \\
\mathrm{n}=74 \\
(38.9 \%)\end{array}$ & $\begin{array}{c}\text { Group } 1 \\
n=3 \\
(1.5 \%)\end{array}$ & $\begin{array}{c}\text { Group } 2 \\
\mathrm{n}=0 \\
(0 \%)\end{array}$ & $\begin{array}{c}\text { Group } 3 \\
\mathrm{n}=118 \\
(59.6 \%)\end{array}$ & $\begin{array}{c}\text { Total } \\
\mathrm{n}=195 \\
(100 \%)\end{array}$ & $\begin{array}{c}\text { Group } 0 \\
\mathrm{n}=193 \\
(67.7 \%)\end{array}$ & $\begin{array}{c}\text { Group } 1 \\
\mathrm{n}=7 \\
(2.4 \%)\end{array}$ & $\begin{array}{c}\text { Group2 } \\
\mathrm{n}=0 \\
(0 \%)\end{array}$ & $\begin{array}{c}\text { Group } 3 \\
\mathrm{n}=86 \\
(29.9 \%)\end{array}$ & $\begin{array}{c}\text { Total } \\
\mathrm{n}=286 \\
(100 \%)\end{array}$ & \\
\hline Height (cm) & $159.0 \pm 0.4$ & $156.7 \pm 5.9$ & - & $157.7 \pm 5.3$ & $158.1 \pm 5.6$ & $165.5 \pm 6.0$ & $164.3 \pm 5.8$ & - & $165.0 \pm 5.7$ & $165.3 \pm 5.9$ & $<0.001$ \\
\hline Weight (kg) & $48.0 \pm 1.5$ & $64.7 \pm 7.9$ & - & $51.1 \pm 4.9$ & $50.1 \pm 5.3$ & $53.0 \pm 6.5$ & $71.0 \pm 5.2$ & - & $57.6 \pm 6.7$ & $54.8 \pm 7.3$ & $<0.001$ \\
\hline $\mathrm{BMI}\left(\mathrm{kg} / \mathrm{m}^{2}\right)$ & $19.0 \pm 1.4$ & $26.3 \pm 2.0$ & - & $20.5 \pm 1.5$ & $20.0 \pm 2.4$ & $19.3 \pm 1.8$ & $26.3 \pm 1.5$ & - & $21.1 \pm 1.9$ & $20.3 \pm 2.3$ & 0.984 \\
\hline possible ( 1 to 10 ) & $6.0 \pm 2.3$ & $3.3 \pm 1.5$ & - & $6.1 \pm 2.4$ & $6.0 \pm 2.4$ & $6.6 \pm 2.2$ & $5.6 \pm 2.6$ & - & $6.3 \pm 2.2$ & $6.5 \pm 2.2$ & 0.012 \\
\hline
\end{tabular}

*The groups are classified into four: Group 0, adolescents who perceived themselves as not fat and not over weight; Group 1, adolescents who perceived themselves as fat and real weight was overweight/obese; Group 2, adolescents who perceived themselves as not fat but real weight was overweight/obese; Group 3 adolescents who perceived themselves as fat but real weight was not overweight/obese. ${ }^{2}$ The result of t-test of Total of Japan and Russia is shown.

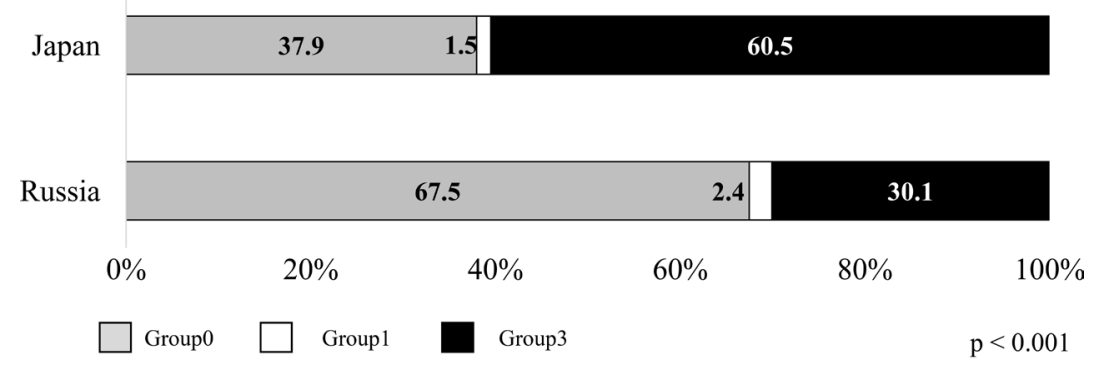

Group 0, adolescents who perceived themselves as not fat and not overweight; Group 1, adolescents who perceived themselves as fat and real weight was overweight/obese; Group 2, adolescents who perceived themselves as not fat but real weight was overweight/obese; Group 3 adolescents who perceived themselves as fat but real weight was not overweight/obese.

Figure 1. Weight perception of Japanese and Russian adolescent girls. 
Table 2. Eating habits of Japanese and Russian girls.

(\%)

\begin{tabular}{|c|c|c|c|c|c|c|c|c|c|}
\hline & \multicolumn{4}{|c|}{ Japan } & \multicolumn{4}{|c|}{ Russia } & \multirow[b]{2}{*}{ p-valu } \\
\hline & $\begin{array}{c}\text { Group } 0 \\
\mathrm{n}=74\end{array}$ & $\begin{array}{c}\text { Group } 1 \\
n=3\end{array}$ & $\begin{array}{l}\text { Group } 3 \\
n=118\end{array}$ & $\begin{array}{c}\text { Total } \\
\mathrm{n}=195\end{array}$ & $\begin{array}{c}\text { Group } 0 \\
n=193\end{array}$ & $\begin{array}{c}\text { Group } 1 \\
n=7\end{array}$ & $\begin{array}{c}\text { Group } 3 \\
n=86\end{array}$ & $\begin{array}{c}\text { Total } \\
\mathrm{n}=\mathbf{2 8 6}\end{array}$ & \\
\hline Breakfast, weekdays ${ }^{1}$ & $64(86.5)$ & $2(66.7)$ & $96(81.4)$ & $162(83.1)$ & $137(71.0)$ & $2(28.6)$ & $49(57.0)$ & $188(65.7)$ & $<0.001$ \\
\hline Fruit $^{2}$ & $10(13.5)$ & $0(0.0)$ & $24(20.3)$ & $34(17.4)$ & $56(29.0)$ & $2(28.6)$ & $23(26.7)$ & $81(28.3)$ & 0.006 \\
\hline Vegitables $^{2}$ & $52(70.3)$ & $2(66.7)$ & $75(63.6)$ & $129(66.2)$ & $62(32.1)$ & $0(0.0)$ & $30(34.9)$ & $92(32.2)$ & $<0.001$ \\
\hline Sweets $^{2}$ & $20(27.0)$ & $1(33.3)$ & $30(25.4)$ & $51(26.2)$ & $67(34.7)$ & $3(42.9)$ & $24(27.9)$ & $94(32.9)$ & 0.129 \\
\hline Coke or softdrink ${ }^{2}$ & $12(16.2)$ & $0(0.0)$ & $14(11.9)$ & $26(13.3)$ & $5(2.6)$ & $0(0.0)$ & $3(3.5)$ & $8(2.8)$ & $<0.001$ \\
\hline
\end{tabular}

${ }^{1}$ The number of people who eat breakfast every day on weekdays. ${ }^{2}$ Shows the number of people eating at least once in a daily. ${ }^{3}$ The result of $\chi$-square test of Total of Japan and Russia is shown.

respect to eating sweets every day $(\mathrm{p}=0.129)$.

\section{Discussion}

This study clarified that Japanese adolescent girls had a large distorted perception of body weight, with $60.5 \%$ of Japanese adolescent girls and $30.1 \%$ of Russian adolescent girls over-perceiving their weight (Figure 1). It was also found that the average BMI is not different between the two countries, but the percentage of adolescents who are on a diet in Japan is higher than those in Russia. In addition, it became clear that many Japanese eat breakfast every day and they do not diet by skipping a meal.

In a survey of adolescents (mean age 14.5 years) in 33 countries across Europe, Israel, and North America, the average percentage of individuals currently trying to lose weight was $7.5 \%$ for boys and $19.8 \%$ for girls [16]. For girls, the countries with the highest percentage of individuals who are trying to lose weight were Denmark (33.7\%), Switzerland (27.3\%), Czech Republic (25.8\%), and Russia (26.6\%). Since Japan has not participated in this HBSC survey, there is no comparative value. However, the results of this study revealed that the trying to lose weight of Japanese adolescents is high among HBSC survey.

Attempts to overweight and lose weight are generally reported to be highest in the groups of Asian countries, and the Japanese results of this study supported a previous study [8]. It suggests that the distorted perception of weight of Japanese adolescent girls is serious.

Haynes A et al. [22] and Jolanda S. van Vliet et al. [17] reported that individuals who have a distorted perception of body weight and see themselves as being overweight are more likely to develop dieting behaviors and intentions. This result supports the results of previous studies. By eliminating the distortion of body weight perception, it is possible to suppress unhealthy weight loss behavior when losing weight is not actually necessary.

Japan does not have a rule that women who are too thin and girls who are too young should not participate in fashion shows and fashion magazines such as 
that in Italy [23], France [24], and Israel [25]. Therefore, Japanese adolescent girls have the opportunity to see many models that are too thin on a daily basis, and the problem is that they think that the body shape of a thin model is beautiful and ideal. The Japanese Society of Eating Disorders launched the "Skinny Model Regulation Working Group" in 2016 [26]. Even in Asia, Japanese adolescent girls have a strong desire to lose weight, so it is desirable to devise rules as soon as possible.

Grace Holland et al. [27] reported that the use of social networking sites (SNSs) is associated with body image and disordered eating. Specific SNS activities, such as viewing and uploading photos and seeking negative feedback via status updates, were identified as particularly problematic. There are reports that Japanese culture and norms affect weight perception [8], and that the use of SNS promotes weight loss behavior [27]. Hence, in the future, it will be necessary to investigate specifically what aspects of culture and how the use of SNS is related to the distortion of the body weight perception of Japanese adolescent girls.

In the developed world, skipping breakfast, and low consumption of vegetables and fruits are common among adolescents [28] [29], and dissatisfaction with body weight has been reported to be related to the habit of skipping breakfast [17]. However, in this study, Japan had more adolescents on a diet than Russia, but only $16.9 \%$ skipped breakfast. This may be due to the fact that in Japan, there is a unique and compulsory system in which nutrition teachers provide dietary education at elementary and junior high schools (6 - 15 years old), and students learn the importance of diet and nutrition from an early age.

Too thin or underweight at a young age is not limited to one's own health issues, such as osteoporosis and abnormal menstrual cycle, and could have a great impact on the next generation [4] [5] [6] [7]. Especially in Japan, the relationship between thin women in their 20s and low-birth-weight infants is regarded as a problem. From a young age, perception of correct body shape and establishment of eating habits are important not only for current health but also for future health. We need to carefully educate adolescent girls that their bodies undergo major changes through secondary sexual characteristics during adulthood.

Finally, since the study is related to the distorted perception of weight in adolescent girls, it was conducted at different times for adolescents in one high school in a local city in Japan and one school in Khabarovsk, Russia. Therefore, the results of this survey do not represent the entire Niigata City and Khabarovsk City. Moreover, this study was carried out only on girls aged 15 years old; therefore, this may not be the case for all adolescent girls. The problem with this study is that the survey times in Japan and Russia are different. Additional research needs to be done at the same time in both the countries to better understand the problem of adolescent girls.

\section{Conclusion}

The results of this study indicate that Japanese adolescent girls are more likely to 
have a distorted perception of body weight and try to lose weight than Russian adolescent girls. Considering the current situation of the number of adolescents having a high desire to lose weight, appropriate health education is necessary.

\section{Acknowledgements}

The authors would like to thank the Japanese and Russian adolescent girls for their cooperation in this study.

\section{Funding}

This study has not received any specific funding.

\section{Conflicts of Interest}

The authors declare no conflicts of interest regarding the publication of this paper.

\section{References}

[1] Kodama, H. (2010) Problems of Underweight in Young Females and Pregnant Women in Japan. Japan Medical Association Journal, 53, 285-289.

[2] Komiyama, Y. (2020) Ministerial notification No. 430 of the Ministry of Health, Labour and Welfare.

https://www.mhlw.go.jp/stf/seisakunitsuite/bunya/kenkou iryou/kenkou/kenkouni ppon21.html

[3] Ministry of Health, Labour and Welfare (2018) National Health and Nutrition Survey Report.

https://www.mhlw.go.jp/stf/seisakunitsuite/bunya/kenkou iryou/kenkou/eiyou/h30 -houkoku 00001.html

[4] Asomaning, K., Bertone-Johnson, E.R., Nasca, P.C., Hooven, F. and Pekow, P.S. (2006) The Association Between Body Mass Index and Osteoporosis in Patients Referred for a Bone Mineral Density Examination. Journal of Women's Health, 15, 1028-1034. https://doi.org/10.1089/jwh.2006.15.1028

[5] Singh, M., Rajoura, O.P. and Honnakamble, R.A. (2019) Menstrual Patterns and Problems in Association with Body Mass Index among Adolescent Schoolgirls. Journal of Family Medicine and Primary Care, 8, 2855-2858. https://doi.org/10.4103/jfmpc.jfmpc 47419

[6] Takimoto, H., Yokoyama, T., Yoshiike, N. and Fukuoka, H. (2005) Increase in Low-Birth-Weight Infants in Japan and Associated Risk Factors, 1980-2000. Journal of Obstetrics and Gynaecology Research, 31, 314-322. https://doi.org/10.1111/j.1447-0756.2005.00294.x

[7] Han, Y.S., Ha, E.H., Park, H.S., Kim, Y.J. and Lee, S.S. (2011) Relationships Between Pregnancy Outcomes, Biochemical Markers and Pre-Pregnancy Body Mass Index. International Journal of Obesity, 35, 570-577. https://doi.org/10.1038/ijo.2010.162

[8] Wardle, J., Haase, A.M. and Steptoe, A. (2006) Body Image and Weight Control in Young Adults: International Comparisons in University Students from 22 Countries. International Journal of Obesity, 30, 644-651. https://doi.org/10.1038/sj.ijo.0803050

[9] Hayashi, F., Takimoto, H., Yoshita, K., and Yoshiike, N. (2006) Perceived Body Size 
and Desire for Thinness of Young Japanese Women: A Population-Based Survey. British Journal of Nutrition, 96, 1154-1162. https://doi.org/10.1017/BJN20061921

[10] Polivy, J. and Herman, C.P. (2004) Sociocultural Idealization of Thin Female Body Shapes: An Introduction to The Special Issue on Body Image and Eating Disorders. Journal of Social and Clinical Psychology, 23, 1-6. https://doi.org/10.1521/jscp.23.1.1.26986

[11] Field, A.E., Javaras, K.M., Aneja, P., Kitos, N., Camargo, C.A., Taylor, C.B., et al. (2008) Family, Peer, and Media Predictors of Becoming Eating Disordered. Archives of Pediatrics and Adolescent Medicine, 162, 574-579. https://doi.org/10.1001/archpedi.162.6.574

[12] Tucci, S. and Peters, J. (2008) Media Influences on Body Satisfaction in Female Students. Psicothema, 20, 521-524.

[13] Neumark-Sztainer, D., Wall, M., Story, M. and Standish, A.R. (2012) Dieting and Unhealthy Weight Control Behaviors during Adolescence: Associations with 10-Year Changes in Body Mass Index. Journal of Adolescent Health, 50, 80-86. https://doi.org/10.1016/j.jadohealth.2011.05.010

[14] Dzielska, A., Kelly, C., Ojala, K., Finne, E., Spinelli, A., Furstova, J., et al. (2020) Weight Reduction Behaviors among European Adolescents-Changes from 2001/2002 to 2017/2018. Journal of Adolescent Health, 66, S70-S80. https://doi.org/10.1016/j.jadohealth.2020.03.008

[15] Ministry of Health, Labour and Welfare (2003). https://www.mhlw.go.jp/houdou/2003/12/h1224-4.html

[16] Ojala, K., Vereecken, C., Välimaa, R., Currie, C., Villberg, J., Tynjälä, J., et al. (2007) Attempts to Lose Weight Among Overweight and Non-Overweight Adolescents: A Cross-National Survey. International Journal of Behavioral Nutrition and Physical Activity, 4, Article No. 50. https://doi.org/10.1186/1479-5868-4-50

[17] Van Vliet, J.S., Gustafsson, P.A. and Nelson, N. (2016) Feeling “Too Fat” Rather Than Being "Too Fat" Increases Unhealthy Eating Habits among Adolescents-Even in Boys. Food and Nutrition Research, 60, 29530. https://doi.org/10.3402/fnr.v60.29530

[18] Pedersen, T.P., Holstein, B.E., Flachs, E.M. and Rasmussen, M. (2013) Meal Frequencies in Early Adolescence Predict Meal Frequencies in Late Adolescence and Early Adulthood. BMC Public Health, 13, Article No. 445. https://doi.org/10.1186/1471-2458-13-445

[19] Chitra, U. and Reddy, C.R. (2007) The Role of Breakfast in Nutrient Intake of Urban Schoolchildren. Public Health Nutrition, 10, 55-58. https://doi.org/10.1017/S1368980007219640

[20] Takano, K., Kinoshita, N., Ishigami, K., Takiguchi, T, Shibayama, J., Zhmerenetsky, K., et al. (2021) Comparative Study of Life Functions of Older People and Supply of Them With Essential Micro- and Microelements in Separate Recoins of Japan and Russia, Bulletin of Public Health. BULLETIN of Public Health and Healthcare Russian Far East. (In Press)

[21] Health Behavior in Schoolaged Children, Word Health Organization Collaborative Cross-National Survey (2017). http://www.hbsc.org/

[22] Haynes, A., Kersbergen, I., Sutin, A., Daly, M. and Robinson, E. (2018) A Systematic Review of the Relationship between Weight Status Perceptions and Weight Loss Attempts, Strategies, Behaviours and Outcomes. Obesity Reviews, 19, 347-363. https://doi.org/10.1111/obr.12634

[23] BBC News (2006) Italy Pact to Stop Skinny Models. 
http://news.bbc.co.uk/2/hi/europe/6204865.stm

[24] BBC News (2015) France Passes Bill Banning "Excessively Thin” Models. http://www.bbc.com/news/world-europe-35130792

[25] Levush, H. (2012) The Library of Congress, Global Legal Monitor, Israel: Restrictions on Depiction of Underweight Models in Commercials.

http://www.loc.gov/law/foreign-news/article/israel-restrictions-on-depiction-of-un derweight-models-in-commercials/

[26] Yamada, H. (2019) Restrictions on Ultra-Skinny Models in Western Countries: Legal Model and Medical Model for Unhealthy Role Models in the Media. Psychiatria et Neurologia Japonica, 121, 479-485.

[27] Holland, G. and Tiggemann, M. (2016) A Systematic Review of the Impact of the Use of Social Networking Sites on Body Image and Disordered Eating Outcomes. Body Image, 17, 100-110. https://doi.org/10.1016/j.bodyim.2016.02.008

[28] Vereecken, C., Dupuy, M., Rasmussen, M., Kelly, C., Nansel, T.R., Al Sabbah, H., et al. (2009) Breakfast Consumption and Its Socio-Demographic and Lifestyle Correlates in Schoolchildren in 41 Countries Participating in the HBSC Study. International Journal of Public Health, 54, 180-190.

https://doi.org/10.1007/s00038-009-5409-5

[29] Sjöberg, A., Barrenäs, M L., Brann, E., Chaplin, J.E., Dahlgren, J., Mårild, S., et al. (2012) Body Size and Lifestyle in an Urban Population Entering Adulthood: The “Grow up Gothenburg” Study. Acta Paediatrica, 101, 964-972.

https://doi.org/10.1111/j.1651-2227.2012.02722.x 


\section{Reference Material}

Questionnaire about Health Behaviors for Japanese and Russian adolescents' girls

1. Are you a boy or a girl?
(1) Boy
(2) Girl

2. How do you think about your life at the moment?

" 10 " is the best possible life and " 1 " is the worst possible life.

(Worst) 12345678910 (Best)

3. Do you think your body is ...?
(1) Too much thin
(2) A bit too thin
(3) About the right size
(4) A bit too fat
(5) Too much fat

4. How many times a week do you usually eat Fruits?
(1) Never
(2) Less than once a week
(3) Once a week
(4) 2 - 4 days a week
(5) 5 - 6 days a week
(6) Once a day, every day (7) Every day, more than once

5. How many times a week do you usually eat Vegetables?
(1) Never
(2) Less than once a week
(3) Once a week
(4) 2 - 4 days a week
(5) 5 - 6 days a week
(6) Once a day, every day (7) Every day, more than once

6. How many times a week do you usually eat Sweets (candy or chocolate)?
(1) Never
(2) Less than once a week
(3) Once a week
(4) 2 - 4 days a week(5) 5 - 6 days a week
(6) Once a day, every day
(7) Every day, more than once

7. How many times a week do you usually drink Coke or other soft drinks that contain sugar?
(1) Never
(2) Less than once a week
(3) Once a week
(4) 2 - 4 days a week(5) 5 - 6 days a week
(6) Once a day, every day
(7) Every day, more than once

8. How much do you weigh without clothes? (In $\mathrm{Kg}$ )

9. How tall are you without shoes?

10. At present are you on a diet or doing something else to lose weight?
(1) No, my weight is fine
(2) No, but I should lose some weight
(3) No, because I need to put on weight
(4) Yes 